\title{
Thrombotic risk in antiphospholipidic syndrome: From hypothesis to current evidence (Review)
}

\author{
CLAUDIA MIHAELA GAVRIȘ ${ }^{*}$, LAURENȚIU DĂNUȚ NEDELCU* ${ }^{*}$ and ALINA MIHAELA PASCU* \\ Faculty of Medicine, ‘Transilvania University’ of Braşov, 500036 Brasov, Romania
}

Received November 6, 2020; Accepted December 8, 2020

DOI: $10.3892 /$ etm.2021.9718

\begin{abstract}
Thirty-five years after it was first described, antiphospholipid syndrome (APS) is unanimously recognized as a systemic autoimmune disease, a major acquired thrombophilia, which can affect any arterial or venous vascular territory, explaining the great diversity of clinical manifestations. The current classification criteria updated in the International Consensus Statement for Definite Antiphospholipid Syndrome from Sydney cannot explain alone the unpredictable evolution with thrombotic events of the patients diagnosed with APS. Although the link to genetics and epigenetics has not been clearly defined as in other autoimmune diseases, it is clear that a proper stratification of thrombotic risk in the era of personalized medicine must include classic biological markers (antiphospholipid antibodies, aPL), along with the already recognized phenotypes, non-conventional serological markers, and additional genetic risk factors for thrombosis. Moreover, with advancing age, a patient with APS develops other thrombotic risk factors which include: hypertension and dyslipidemia among others. According to the classification criteria, a patient is considered to have a low, moderate or high thrombotic risk. In clinical practice, patients with the same risk score may have completely different evolutions in terms of the recurrence of thrombosis. Concerning this approach, it appears that new non-conventional serological markers, phenotype-assessment and genetic determinants have an increasing importance and should be reconsidered in a proper thrombotic risk evaluation in patients with APS, compared to the initial concept of APS as first defined.
\end{abstract}

Correspondence to: Professor Laurențiu Dănuț Nedelcu, Faculty of Medicine, 'Transilvania University' of Brașov, 29 Eroilor Street, 500036 Brasov, Romania

E-mail: laurnedelcu@yahoo.com

*Contributed equally

Key words: antiphospholipid syndrome, antiphospholipid antibodies, thrombosis, risk assessment, anticardiolipin antibodies, lupus anticoagulant, anti- $\beta_{2}$ glycoprotein- 1 antibodies

\section{Contents}

1. Introduction

2. Non-conventional/emerging antiphospholipid syndrome serologic markers

3. Phenotype assessment of antiphospholipid syndrome

4. Genetics of antiphospholipid syndrome

5. Conclusions and perspectives

\section{Introduction}

Thirty five years after it was first described, antiphospholipid syndrome (APS) is unanimously recognized as a systemic autoimmune disease, a major acquired thrombophilia, which can affect any arterial or venous vascular territory, explaining the great diversity of clinical manifestations $(1,2)$. Patients with APS are at a high risk for developing thrombotic arterial, venous and obstetric complications (recurrent pregnancy loss). The diagnostic criteria include the presence of any of the clinical criterion mentioned above plus at least one laboratory criterion out of three possible antiphospholipid antibodies (aPLs): i) IgG and $\mathrm{IgM}$ anticardiolipin (aCL) at a titer $>40 \mathrm{IU} / \mathrm{ml}$; ii) lupus anticoagulant (LA); iii) anti- $\beta_{2}$ glycoprotein- 1 antibodies $\left(\mathrm{a} \beta_{2} \mathrm{GPI}\right)$. Medium/high titer of $\mathrm{aCL} / \mathrm{a} \beta_{2}$ GPI has been defined as $>99$ th percentile. Low-titer aCL/a $\beta_{2}$ GPI positivity ( $>95$ th to $<99$ th percentile) is considered positive for obstetric but not for thrombotic APS $(1,2)$.

Thrombotic risk assessment in patients with APS is essential for establishing an appropriate treatment for the primary and secondary prophylaxis of arterial or venous and obstetrical thrombotic events which define the clinical picture. In the assessment of the thrombotic risk, the role of classical serological markers is limited. Galli et al (3) proposed three major modifications: implementing strict guidelines for the performance of LA assays, excluding aCL assays from the criteria, despite the fact they are currently used and, restricting the measurement of a $\beta_{2}$ GPI antibodies to IgG. Efforts to standardize antiphospholipid antibody assays have been reported (3-8).

There is currently no predictive factor for the evolution of thrombotic complications in APS. There are studies that have evaluated the role of a high titer of aPL/LA, and, respectively, the association of several laboratory criteria, with controversial results. Patients with a high aPL titer and the presence of all 
three biological markers do not always evolve with recurrent thrombosis (more than 2) and vice versa (9-14).

For a proper antibody profile of these patients, all of the three tests should be performed at the same time, and should be positive on at least two different testing occasions at least 12 weeks apart. Triple-positive patients (aCL, LA and a $\beta_{2}$ GPI $\mathrm{IgG}$ and $\operatorname{IgM})$ are at high risk for thrombosis and APS-related pregnancy morbidity $(1,15)$.

A few studies have evaluated the $\beta_{2}$ GPI domain I antibodies (aDI), a subgroup of $\mathrm{a} \beta_{2} \mathrm{GPI} \operatorname{IgG}$, as an independent risk factor for thrombosis, and have revealed that $\mathrm{aD} 1$ had no added value to the current aPL diagnostic panel $(16,17)$.

Therefore, the overall thrombotic risk of a patient with APS may be influenced by other prothrombotic factors, representing sort of a second hit to trigger a new thrombotic event.

\section{Non-conventional/emerging antiphospholipid syndrome serologic markers}

APS is an autoimmune disease that may have a predictable course, similar to other autoimmune diseases. Upon appearance of the first diagnostic marker, the diagnosis of seropositive APS is established. Yet, but there are also forms of seronegative APS. In this circumstance, an emerging second generation of diagnostic biological markers has been described: IgG and IgM directed against phosphatidylserine (PS), prothrombin (PT), phosphatidylserine/prothrombin (PS/PT) complex, and against phosphatidic acid (PA), phosphatidyl-ethanolamine (PE), phosphatidyl-glycerol (PG), phosphatidyl-inositol (PI), Annexin V (A5), and Annexin II (A2). To date, there are studies that have evaluated the frequency of their association in patients with seronegative APS (15-20). Which of these non-conventional, emerging biological markers has a predictive role for the evolution of recurrent thrombosis in APS warrants further investigation. Whether the positivity for multiple non-conventional markers should be considered as alternative predictors of a severe APS evolution has to be substantiated by further research.

In another autoimmune disease, rheumatoid arthritis, the second generation of biological markers has proven to have a much better predictive role for the evolution of erosive forms of arthritis than the first generation of markers, represented by the rheumatoid factor (18-20).

Antibodies against the PS/PT complex are not included in the APS laboratory criteria but their positivity has been recently proposed as a part of the global APS score (GAPSS), and has been shown to be a strong prognostic factor for both arterial and venous thrombosis (21-23).

\section{Phenotype assessment of antiphospholipid syndrome}

As in other autoimmune diseases, several disease phenotypes have been described in APS. Sciascia et al conducted a significant study by performing cluster analysis on a large cohort of patients with APS and identified 5 distinct clusters: Clusters 1, 2, 3 and 5 corresponded to well-known entities, such as primary thrombotic APS (PAPS), APS associated with systemic lupus erythematosus (SLE), secondary APS (SAPS), obstetric APS, and cluster 4 . Cluster 4 included aPL patients (aPL carriers) with the highest prevalence of cytopenia (mainly thrombocytopenia) when compared to cluster 1 and cluster 2. Thrombotic risk appeared to correlate with the disease phenotype (24).

\section{Genetics of antiphospholipid syndrome}

Among the associated prothrombotic factors in patients with APS, genetic thrombophilia is not yet sufficiently evaluated in routine clinical practice. Patients already enrolled for long-term/life-long anticoagulant treatment are currently not always fully evaluated for a possible association with thrombophilia (25-28).

Interactions between acquired and genetic risk factors become increasingly related to a higher thrombotic risk. Many studies have determined the prevalence of common gene polymorphisms in patients with aPL. Some of these polymorphisms affect proteins directly related to aPLs $\left(\beta_{2}\right.$ GPI gene polymorphisms), others affect normal hemostasis components (tissue factor pathway inhibitor, thrombomodulin THMD mutations, polymorphism in the factor XIII gene, polymorphisms in platelet Fc gamma-receptor IIA), and others are related to immune or inflammatory pathways (endothelial protein $\mathrm{C}$ receptor, P-selectin glycoprotein ligand-1 gene, CD40 ligand gene) (29-32).

Patients with PAPS may be associated with a clinically underestimated genetic thrombophilia that may be responsible for triggering thrombotic events (25).

Thrombotic risk assessment scores in patients with APS do not include genetic or acquired thrombophilia, and concerning unconventional serological markers, only the antibody anti-phosphatidylserine/prothrombin complex (aPS/PT) IgG and IgM I is considered (22). These antibodies have been shown to be more useful in thrombotic risk assessment than anti-PT and, respectively, anti-PS antibodies alone, and may coexist in the same patient (33-35).

The heterogeneity of thrombotic manifestations in patients with APS suggests a possible intervention of other additional risk factors which may contribute to their prothrombotic profile. Among this, several studies have described the coexistence of numerous genetic risk factors for thrombosis: Leiden factor $\mathrm{V}$, antithrombin deficiency, methylentetrahydrofolate-reductase (MTHFR), homocysteine, protein $\mathrm{C}$ or protein $\mathrm{S}$ deficiency, acquired activated-protein $\mathrm{C}$ resistance $(19,30,36,37)$.

\section{Conclusions and perspectives}

For a systemic autoimmune disease clinically defined by thrombotic complications, as APS is to date considered, in clinical practice it is essential to stratify the global thrombotic risk. Considering the multitude of (major or minor) genetic or acquired factors that interfere with this risk, each patient represents a distinct entity. In the evolution towards personalized medicine, genome-wide linkage analysis and larger cohort case-control association studies, as well as multicenter international collaborators such as the Antiphospholipid Syndrome Alliance for Clinical Trials and International Networking (APS ACTION) (19) must address crucial questions such as:

Do non-conventional, emerging biological markers (that are not commonly evaluated in patients with seropositive APS) somehow play a predictive role in the evolution of recurrent thrombosis? Is the course of recurrent thrombosis in patients 
with a reduced titer and/or the presence of a single laboratory diagnostic criterion (aCL, LA or a $\beta_{2} \mathrm{GPI}$ ) significantly determined by the association of thrombophilia?

\section{Acknowledgements}

Not applicable.

\section{Funding}

No funding was received.

\section{Availability of data and materials}

All information provided in this review is documented by relevant references.

\section{Authors' contributions}

CMG and AMP performed the literature search for relevant publications on the topic. CMG, LDN and AMP participated in drafting the manuscript and provided critical insight. All the authors verified and approved the final version of the manuscript.

\section{Ethics approval and consent to participate}

Not applicable.

\section{Patient consent for publication}

Not applicable.

\section{Competing interests}

The authors declare that they have no competing interests.

\section{References}

1. Miyakis S, Lockshin MD, Atsumi T, Branch DW, Brey RL, Cervera R, Derksen RH, DE Groot PG, Koike T, Meroni PL, et al: International consensus statement on an update of the classification criteria for definite antiphospholipid syndrome (APS). J Thromb Haemost 4: 295-306, 2006.

2. Gardiner C, Hills J, Machin SJ and Cohen H: Diagnosis of antiphospholipid syndrome in routine clinical practice. Lupus 22: $18-25,2013$.

3. Galli M, Reber G, de Moerloose P and de Groot PG: Invitation to a debate on the serological criteria that define the antiphospholipid syndrome. J Thromb Haemost 6: 399-401, 2008.

4. Tincani A, Andreoli L, Casu C, Cattaneo R and Meroni P: Antiphospholipid antibody profile: Implications for the evaluation and management of patients. Lupus 19: 432-435, 2010.

5. Kelchtermans H, Pelkmans L, de Laat B and Devreese KM: $\mathrm{IgG} / \mathrm{IgM}$ antiphospholipid antibodies present in the classification criteria for the antiphospholipid syndrome: A critical review of their association with thrombosis. J Thromb Haemost 14: $1530-1548,2016$.

6. Tektonidou MG, Andreoli L, Limper M, Amoura Z, Cervera R, Costedoat-Chalumeau N, Cuadrado MJ, Dörner T, Ferrer-Oliveras R, Hambly $\mathrm{K}$, et al: EULAR recommendations for the management of antiphospholipid syndrome in adults. Ann Rheum Dis 78: 1296-1304, 2019.

7. Garcia D and Erkan D: Diagnosis and management of the antiphospholipid syndrome. N Engl J Med 378: 2010-2021, 2018.

8. Montagnana M, Lippi G and Danese E: An overview of thrombophilia and associated laboratory testing. Methods Mol Biol 1646: 113-135, 2017.
9. Galli M, Luciani D, Bertolini G and Barbui T: Lupus anticoagulants are stronger risk factors for thrombosis than anticardiolipin antibodies in the antiphospholipid syndrome: A systematic review of the literature. Blood 101: 1827-1832, 2003.

10. Chayoua W, Kelchtermans H, Moore GW, Musiał J, Wahl D, de Laat B and Devreese KM: Identification of high thrombotic risk triple-positive antiphospholipid syndrome patients is dependent on anti-cardiolipin and anti- $\beta 2$ glycoprotein I antibody detection assays. J Thromb Haemost 16: 2016-2023, 2018.

11. Hughes GR and Khamashta MA: 'Seronegative antiphospholipid syndrome': An update. Lupus 28: 273-274, 2019.

12. Chayoua W, Kelchtermans H, Gris JC, Moore GW, Musiał J, Wahl D, de Groot PG, de Laat B and Devreese KM: The (non-) sense of detecting anti-cardiolipin and anti- $\beta 2$ glycoprotein I IgM antibodies in the antiphospholipid syndrome. J Thromb Haemost 18: 169-179, 2020.

13. Campello E, Spiezia L, Adamo A and Simioni P: Thrombophilia, risk factors and prevention. Expert Rev Hematol 12: 147-158, 2019.

14. Gavris C, Poroch V, Simion L, Baracan A, Toader E and Pascu AM: Biochemical markers with low-grade inflammation as predictors of thrombotic events in antiphospholipid syndrome. Rev Chim 68: 1586-1590, 2017.

15. Devreese KM, Ortel TL, Pengo V and de Laat B: Laboratory criteria for antiphospholipid syndrome: Reply. J Thromb Haemost 16: 2117-2119, 2018.

16. De Craemer AS, Musial J and Devreese KM: Role of anti-domain 1- $\beta 2$ glycoprotein I antibodies in the diagnosis and risk stratification of antiphospholipid syndrome. J Thromb Haemost 14: $1779-1787,2016$.

17. Iwaniec T, Kaczor MP, Celińska-Löwenhoff M, Polański S and Musiał J: Clinical significance of anti-domain $1 \beta 2$-glycoprotein I antibodies in antiphospholipid syndrome. Thromb Res 153: 90-94, 2017.

18. Pignatelli P, Ettorre E, Menichelli D, Pani A, Violi F and Pastori D: Seronegative antiphospholipid syndrome: Refining the value of 'non-criteria' antibodies for diagnosis and clinical management. Haematologica 105: 562-572, 2020.

19. Sciascia S, Baldovino S, Schreiber K, Solfietti L, Radin M, Cuadrado MJ, Menegatti E, Erkan D and Roccatello D: Thrombotic risk assessment in antiphospholipid syndrome: The role of new antibody specificities and thrombin generation assay. Clin Mol Allergy 14: 6, 2016.

20. Litvinova E, Darnige L, Kirilovsky A, Burnel Y, de Luna G and Dragon-Durey MA: Prevalence and Significance of non-conventional antiphospholipid antibodies in patients with clinical APS criteria. Front Immunol 9: 2971, 2018.

21. Otomo K, Atsumi T, Amengual O, Fujieda Y, Kato M, Oku K, Horita T, Yasuda S and Koike T: Efficacy of the antiphospholipid score for the diagnosis of antiphospholipid syndrome and its predictive value for thrombotic events. Arthritis Rheum 64: 504-512, 2012.

22. Sciascia S, Sanna G, Murru V, Roccatello D, Khamashta MA and Bertolaccini ML: GAPSS: The Global Anti-Phospholipid Syndrome Score. Rheumatology (Oxford) 52: 1397-1403, 2013.

23. Sciascia S, Sanna G, Murru V, Roccatello D, Khamashta MA and Bertolaccini ML: Anti-prothrombin (aPT) and anti-phosphatidylserine/prothrombin (aPS/PT) antibodies and the risk of thrombosis in the antiphospholipid syndrome. A systematic review. Thromb Haemost 111: 354-364, 2014.

24. Sciascia S, Radin M, Cecchi I, Bertolaccini ML, Bertero MT, Rubini E, Vaccarino A, Bazzan M, Giachino O, Baldovino S, et al: Identifying phenotypes of patients with antiphospholipid antibodies: results from a cluster analysis in a large cohort of patients. Rheumatology (Oxford), 2019 (Ahead of print).

25. Forastiero R, Martinuzzo M, Adamczuk Y, Varela ML, Pombo G and Carreras LO: The combination of thrombophilic genotypes is associated with definite antiphospholipid syndrome. Haematologica 86: 735-741, 2001.

26. Pengo V: A contribution to the debate on the laboratory criteria that define the antiphospholipid syndrome. J Thromb Haemost 6: 1048-1049, 2008.

27. Pengo V, Ruffatti A, Legnani C, Gresele P, Barcellona D, Erba N, Testa S, Marongiu F, Bison E, Denas G, et al: Clinical course of high-risk patients diagnosed with antiphospholipid syndrome. J Thromb Haemost 8: 237-242, 2010.

28. Wahl D: 'Antiphospholipids': The more, the worse? Blood 131: 2092-2094, 2018.

29. Atsumi T, Bertolaccini ML and Koike T: Genetics of antiphospholipid syndrome. Rheum Dis Clin North Am 27: 565-572, 2001 . 
30. Castro-Marrero J, Balada E, Vilardell-Tarrés M and Ordi-Ros J: Genetic risk factors of thrombosis in the antiphospholipid syndrome. Br J Haematol 147: 289-296, 2009.

31. Yonal I, Hindilerden F, Hancer VS, Artim-Esen B, Daglar A, Akadam B, Nalcaci M and Diz-Kucukkaya R: The impact of platelet membrane glycoprotein Ib alpha and Ia/IIa polymorphisms on the risk of thrombosis in the antiphospholipid syndrome. Thromb Res 129: 486-491, 2012.

32. Iuliano A, Galeazzi M and Sebastiani GD: Antiphospholipid syndrome's genetic and epigenetic aspects. Autoimmun Rev 18: $102352,2019$.

33. Diz-Kucukkaya R, Hancer VS, Artim-Esen B, Pekcelen Y and Inanc $\mathrm{M}$ : The prevalence and clinical significance of inherited thrombophilic risk factors in patients with antiphospholipid syndrome. J Thromb Thrombolysis 29: 303-309, 2010.
34. Berman H, Ugarte-Gil MF, Espinosa G, Tàssies D, Monteagudo J, Reverter JC and Cervera R: Can inherited thrombophilia modulate the clinical phenotype of patients with antiphospholipid syndrome? Clin Exp Rheumatol 31: 926-932, 2013.

35. Hotoleanu C: Genetic risk factors in venous thromboembolism. Adv Exp Med Biol 906: 253-272, 2017.

36. Negrini S, Pappalardo F, Murdaca G, Indiveri F and Puppo F: The antiphospholipid syndrome: From pathophysiology to treatment. Clin Exp Med 17: 257-267, 2017.

37. Islam MA, Khandker SS, Alam F, Kamal MA and Gan SH: Genetic risk factors in thrombotic primary antiphospholipid syndrome: A systematic review with bioinformatic analyses. Autoimmun Rev 17: 226-243, 2018. 